\title{
A RARE CASE OF FOREIGN BODY (DETACHED PORTEX TRACHEOSTOMY TUBE) IN THE BRONCHUS: CASE REPORT
}

Ravi Kishore H. ${ }^{1}$, Channabasappa M.J², Arun Ingale ${ }^{3}$

\section{HOW TO CITE THIS ARTICLE:}

Ravi Kishore H, Channabasappa M.J, Arun Ingale. "A Rare case of Foreign Body (Detached Portex Tracheostomy Tube) in the Bronchus: Case Report". Journal of Evolution of Medical and Dental Sciences 2014; Vol. 3, Issue 04, January 27; Page: 835-837, DOI: 10.14260/jemds/2014/1912

ABSTRACT: Tracheostomy is a common airway procedure for life support. Fractured/detached and hence aspiration of a tracheostomy tube in the tracheobronchial tree is a rare late complication which can be life threatening sometimes. Published reports of a fractured metallic tracheostomy tube presenting as a foreign body in the tracheobronchial tree are rare and detached portex tracheostomy tube are even rarer. Here we are reporting a rare case of detached part of portex tracheostomy tube presenting as a foreign body in the right bronchus. Therapeutic rigid bronchoscopic removal is the mainstay of treatment. A periodic review of the techniques of tracheostomy care including timely checkups for signs of wear and tear can possibly eliminate such avoidable late complications.

KEYWORDS: Portex tracheostomy tube, tracheostomy tube complications, foreign body bronchus, tracheostomy care.

INTRODUCTION: Tracheostomy is a common airway procedure for life support. This procedure is safe, although occasional early and late complications are known to occur. Fracture and hence aspiration of a tracheostomy tube in the tracheobronchial tree is rare late complication which can be life threatening. Published reports of fractured Tracheostomy tube presenting as foreign body in tracheobronchial tree are few. ${ }^{1-3}$

CASE REPORT: A 70 year old female patient presented to our out- patient department VIMS, Bellary, two days after the missing inner tube of the PORTEX Tracheostomy tube (no.7 uncuffed) having had only outer neck plate with signs of respiratory distress and stridor. Her medical reports showed, she had undergone tracheostomy at this same institute for suspected transglottic malignancy with stridor with left lung lower lobe collapse. On examination her vitals were normal. Neck examination showed stomal stenosis. On auscultation, chest revealed decreased breath sounds bilaterally. A subsequent digital X-ray of the chest APview clearly outlined the part of that missing portex tracheostomy inner tube, lodged in the right main bronchus with old left lung lower lobe collapse (fig-1).

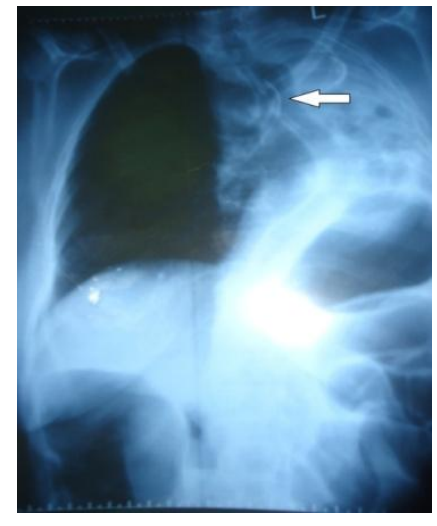

Fig.1: X-raychest AP view showing foreign

body in right bronchus with old left lower

lobe collapse and tracheal deviation

towards left. (Pointing radio-opaque

marker of the detached inner tube) 
She was immediately shifted to the operating room for a rigid bronchoscopic removal under general anesthesia. Since the patient upper airway was already compromised by previous pathology and the stomal stenosis, general anesthesia was deferred and the procedure was done under local infiltration around stomal opening ( $2 \%$ xylocaine with adrenaline -premixed) followed by $2 \mathrm{cc}$ of $4 \%$ xylocaine instillation into the trachea. Tracheostomy stoma was widened to facilitate rigid bronchoscopy. It was noted that the patient was relieved of stridor on widening the stoma. The portex inner tube was retrieved from the right main bronchus through tracheostomy stoma with the aid of a long foreign body bronchoscopy forceps. Detachment at the junction between the inner tube and the neck plate was found (fig. 2 and 3 ).

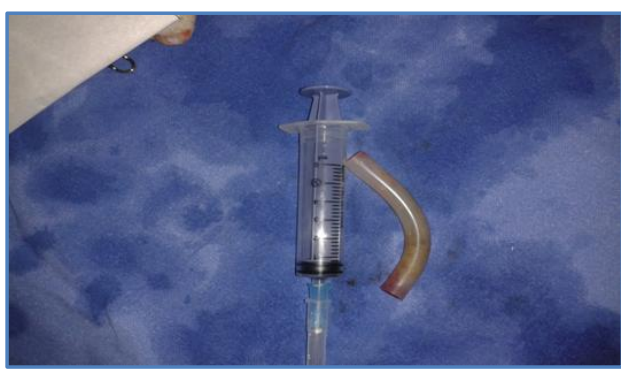

Fig.2 showing detatched inner tube of the portex tracheostomy tube from its neck plate.

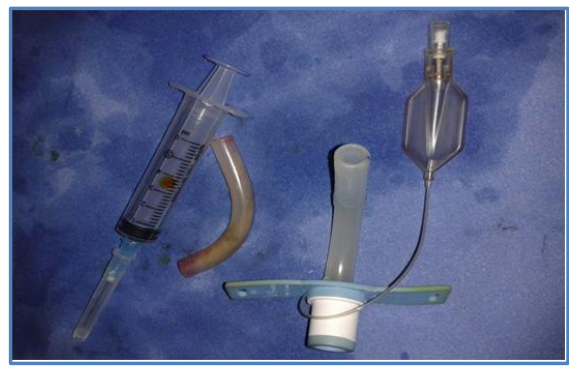

Fig. 3: comparision of detatched $\&$ normal portex tracheostomy tube after its removal from the bronchus.

A metallic (Fuller's tracheostomy tube no.36) was used to replace the detached portex tube. Patient was discharged after her status was stable with an advice on proper maintenance of tracheostomy tube.

DISCUSSION: Various objects have been reported as overlooked foreign bodies in tracheobronchial tree. The first case of report of a metallic tracheostomy tube was in 1960 by Bassoe and Boe ${ }^{1}$, since then, this complication has been published in the literature periodically. The largest series of fractured tracheostomy tubes reported to date by Gupta in $1987^{2}$ was of nine cases reported over a period of about 8 years. Modern metallic tracheostomy tubes are made from stainless steel, which are supposed to be less corrosive and less likely to fracture. Despite this a Majority of the cases of fractured tubes reported in literature have been metallic ${ }^{4}$. The most common reported fracture site is at the junction between the tube and the neck plate ${ }^{3-5}$. Prolonged usage leading to the wear and tear of the tubes has been proposed as the major risk factor for tracheostomy tube fracture. The most common dislodged site reported was the trachea and the right main bronchus 5 . The prolonged stay of a foreign body in the bronchial tree can lead to irreversible pulmonary changes ${ }^{7}$ due to mechanical pressure effects, chemical reactions and at times can lead to even malignant transformation.

In most cases, the diagnosis is obvious in a chest radiograph ${ }^{2}$. Computed tomography Thorax with bronchoscopy is helpful in ascertaining the exact position of the fractured/detached fragment in relation to the tracheobronchial tree in longstanding cases especially when chest disease is suspected 8 .

Foreign body aspiration is a serious medical emergency demanding timely recognition and prompt action. Therapeutic rigid bronchoscopy is the mainstay of the treatment ${ }^{6}$, since a larger 
foreign body such as broken portex tracheostomy tube may not be retrievable with a flexible bronchoscope. In cases where in the fractured fragment is lying just below the tracheostomy stoma removal under direct vision is possible.

A relieving incision at the site of narrow tracheostomy opening may be required in some instance. In our case, since stomal stenosis was already present the preferred method of extraction of foreign body is by recannulation of stoma and retrieval of foreign body through the same.

CONCLUSION: A periodic review of the techniques of the tracheostomy care ${ }^{6}$ including timely checkups for signs of wear and tear can possibly eliminate such avoidable late complications ${ }^{8}$.

\section{REFERENCS:}

1. Bassoe HH, Boe J. Broken tracheotomy tube as a foreign body. Lancet. 1960; 1:1006-7. [PubMed].

2. Gupta SC. Fractured tracheostomy tubes in the tracheobronchial tree: A report of nine cases. J Laryngol Otol. 1987; 101:861-7. [PubMed].

3. Gupta SC, Ahluwalia H. Fractured tracheostomy tube: An overlooked foreign body. J Laryngol Otol. 1996; 110:1069-71. [PubMed]

4. Piromchai $\mathrm{P}$, Lertchanaruengrit $\mathrm{P}$, Vatanasapt $\mathrm{P}$, Ratanaanekchai $\mathrm{T}$, Thanaviratananich S. Fractured metallic tracheostomy tube in a child: A case report and review of the literature. J Med Case Reports. 2010; 4:234. [PMC free article] [PubMed]

5. Alqudehy ZA, Alnufaily YK. Fractured tracheostomy tube in the tracheobronchial tree of a child: Case report and literature review. J Otolaryngol Head Neck Surg. 2010; 39:E70-3. [PubMed]

6. White AC, Kher S, O'Connor HH. When to change a tracheostomy tube. Respir Care. 2010; 55:1069-75. [PubMed]

7. Hagibour A, Khan ZH. Fracture and aspiration of metallic tracheostomy tube. Saudi Med J. 2007; 28:468. [PubMed]

8. Arvind Krishnamurthy and R Vijayalakshmi Broken tracheostomy tube: A fractured mandate J Emerg Trauma Shock. 2012 Jan-Mar; 5(1): 97-99. doi: 10.4103/0974-2700.93098.

\section{AUTHORS:}

1. Ravi Kishore H.

2. Channabasappa M.J.

3. Arun Ingale

\section{PARTICULARS OF CONTRIBUTORS:}

1. Associate Professor, Department of ENT, Vijayanagara Institute of Medical Sciences, Bellary, Karnataka, India.

2. PG Student, Department of ENT, Vijayanagara Institute of Medical Sciences, Bellary, Karnataka, India.

3. PG Student, Department of ENT, Vijayanagara Institute of Medical Sciences, Bellary, Karnataka, India.

\author{
NAME ADDRESS EMAIL ID OF THE \\ CORRESPONDING AUTHOR: \\ Dr. Ravi Kishore H., \\ Associate Professor, \\ Department of E.N.T., \\ Vijayanagara Institute of Medical Sciences, \\ Bellary, Karnataka, India. \\ E-mail: ravikishore_ent@yahoo.com
}

Date of Submission: 06/01/2014. Date of Peer Review: 07/01/2014. Date of Acceptance: 17/01/2014. Date of Publishing: 21/01/2014. 